\title{
A new model for planning the distributed facilities locations under emergency conditions and uncertainty space in relief logistics
}

\author{
Ardavan Babaei and Kamran Shahanaghi*
}

Department of Industrial Engineering, Iran University of Science and Technology, Tehran, Iran

\begin{tabular}{l}
\hline C H R O N I C L E \\
\hline Article history: \\
Received July 2, 2016 \\
Received in revised format \\
September 10, 2016 \\
Accepted October 212016 \\
Available online \\
October 212016 \\
\hline Keywords: \\
Relief logistics \\
Uncertainty space \\
NSGA-II \\
E-Constraint \\
Emergency conditions
\end{tabular}

\begin{abstract}
A B S T R A C T
The life of many people across the world can face various dangers with incurrence of incidents and unpredictable diseases. Incidents often require quick relief as they directly affect human lives. The process of planning, management and monitoring the flow of relief sources to injured and sick individuals is called relief logistics. When best relief services are provided through available sources, relief logistics appear. In this article, a multi-objective model for relief resources distribution facilities under an uncertain condition is investigated in two ways of demand satisfaction by considering the relief resources accessibility and demand satisfaction in a fuzzy logic. In the presented model, the concepts of cost, chance of demand satisfaction, elevation of response capability of system, discount levels for relief commodities, late satisfaction of demand, hub for accumulation of late and returned orders and special route for time significance in distribution of relief commodities are considered. For the first problem, the chance of relief resources accessibility and for the second problem, demands were investigated using fuzzy logic. Considering the conducted analysis, the demand amount is taken more in the second problem than the first one, which has led to an increase in the cost of the second problem. On one hand, the chance of demand satisfaction with no late orders is higher than the second problem. Satisfaction of demand occurs more in the second problem as well. Thus, these problems should be utilized in a way that suits the space of this problem. To solve the problem and to do the sensitivity analysis, we present a NSGA-II algorithm to deal with multi-objectiveness of the problem. A $\varepsilon$-Constraint method is also proposed to evaluate the performance of the proposed algorithm.
\end{abstract}

\section{Introduction}

Response planning to reach people's requirements when natural disasters such as hurricanes, floods, and earthquakes happens is a challenging task because resources of more than one type must be offered on time. It also needs a properly planned process of obtaining and distributing the necessary resources. This creates more challenges as the demand in such disasters may differ over time base on the kinds of materials, services or in terms of quantities. Disasters are categorized in terms of uncertainty and unpredictability; and thus, demand may change quickly in such an environment (Swiss, 2015). Moreover, demand for resources in one location at a particular period may not necessarily exist in the next period; or, a specific location may require a very high demand in the subsequent period.

* Corresponding author

E-mail address: shahanaghi@iust.ac.ir (K. Shahanaghi)

(C) 2017 Growing Science Ltd. All rights reserved.

doi: $10.5267 /$ j.uscm.2016.10.004 
Performance of emergency services is normally computed in terms of the response time as well as the total logistics cost. Thus, when demand is not met on time, the performance of service will get worse. In order to study such circumstance, a flexible and efficient emergency response system have to be built so that both social and economic losses could be minimized (Balcik, et al., 2008). Thus, location and allocation of relief distribution facilities play essential role for an effective emergency response planning in addition to ambulance and helicopter routing and assignment problem. The issue of the humanitarian logistics operation can be categorized in different levels including one-level (Overstreet et al., 2011), two-level (Tzeng, et al., 2007) and multi-level (Balcik, et al., 2008). The number of facilities in this category of problems includes one-facility and multi-facilities (Jotshi, et al., 2009). The scale of transport fleet was studied for one vehicle and several vehicles (Tzeng et al., 2007).

According to Ratick et al. (2009), the emergency request may happen and can be studied using fuzzy programming for the uncertain humanitarian logistics operations. Mete and Zabinsky (2010) showed that accessibility of facilities and paths could be considered by two criteria of certain and probable. The limitation of facilities capacity in all types of models is active and sometimes passive. The emergency vehicles are considered in two types of either with/without capacity. The time window is considered in three categories of unlimited time (Mete \& Zabinsky, 2010), soft time window (Balcik \& Beamon, 2008) and hard time window (Ozdamar, et al., 2004). The humanitarian logistics model can perform the delivery operation (Mete and Zabinsky, 2010), loading (Batta, 2009) and simultaneous delivery and loading (Campbell et al., 2008) in the stations. The type of path is defined in two types of open (Jotshi, et al., 2009) and closed (Hale and Moberg, 2005). The location of customers in the network needs routing of nodes (Mete and Zabinsky, 2010; Sheu, 2007) or edges (Campbell et al., 2008). The type of target functions is cost (Rawls et al., 2010), humanitarian (Jotshi, et al., 2009) or the combination of the two which is one-objective (Özdamar et al., 2004; Mete \& Zabinsky, 2010), two or multiple objectives (Mete \& Zabinsky, 2010). These models can be employed under crisis such as earthquake (Özdamar et al., 2004; Mete \& Zabinsky, 2010), flood (Doerner et al., 2008) etc. The method of solving these models are precise (Balcik et al., 2008), meta-heuristic (Paul \& Batta, 2008), heuristic (Doerner et al., 2008). The decision-making levels in these problems is strategic (Doerner et al., 2008), tactical (Mete \& Zabinsky, 2010) or operational (Mete \& Zabinsky, 2010; Özdamar et al., 2004). The time horizon in these issues is static (Doerner et al., 2008; Mete \& Zabinsky, 2010) or dynamic (Özdamar et al., 2004). The type of consignment in the humanitarian logistics problems can be goods (Özdamar et al., 2004; Mete \& Zabinsky, 2010), human beings (Drezner, 2007) or a combination of these two. In some other papers, the response procedure of the ambulances is analyzed based on the categorization of the patients and the request areas in big problems which is uncertain for reaching the best location and also the studies based on regression for enhancing the pre-hospital services such as ambulances is studied (Hashzemi et al., 2014).

Modeling of the locating problems of emergency facilities with the world war two has emerged in the scientific discussions and the researchers pay special attention to the research in this field. The 1970s decade can be considered the commencement of modeling of emergency facilities locating. Moeini et al. (2015) proposed a model to detect the most emergency locations. Other used different objectives. The first model used minimizing the response time instead of target envelopment function (Swoveland et al., 1973). Berlin and Liebman (1974) presented the first dynamic model simply in 1974. Also Schilling et al. (1979) represented the facility location equipment emplacement technique and tandem equipment allocation model with several types of servers.

In the years between 1970 until 1980 most of the models were considered under certain condition and uncertainty was less considered in the parameters. The first probable model was proposed in 1978 (Aly $\&$ White, 1978) and in the 1980s decade most of the researchers considered the models to be probable and parameters to be random. Also in this period the models with supportive cover (Hogan \& Revelle, 1986) were most in attention. One of the most important probable with envelopment target function 
which provides a field for using of probable models was presented by Daskin (1983). Moreover in this period locating-assignment (Pirkul \& Schilling, 1988) models were considered. The first review model which categorized the emergency facilities models was presented by ReVelle (1989). Also Matsutomi and Ishii (1992), for the first time, employed the fuzzy concept in the modeling and solving the emergency locating problems. The first model with considering the reliability was presented by Ball and Lin (1993). Also, Marianov and Serra (1996) used the queue theory in their model.

From 1990 to 2000 the researchers developed the existing models by focusing on different models and there was a great attention on multiple objective models. In 2004 the partial cover model was presented by Karasakal and Karasakal (2004) which solves the main problem of maximal covering location planning (MCLP) model. Erkut et al., (2009) evaluated and developed the MCLP in 4 different states. Berman et al. (2007) used the transfer point concept in their paper for the first time. Also Erkut et al. (2007) presented the significant model of MSLP with the development and troubleshooting. Heuristic and meta-heuristic models have also been used extensively. For instance, Rajagopalan et al. (2007) compared 4 meta-heuristic models for solving the MEXCLP problem which was presenter by Daskin (1983).

Different models in the fields of crisis based on the transport and distribution on the humanitarian logistics have been investigated. In the files of transportation, the models are based on cost, time and number. The models based on the cost include the cost of travel which is comprised of maintenance and repair and distance and choosing the source with regards to the capacity and the supported area and the extent of flow under evaluation (Ben-Tal, 2011). Based on the purpose we should minimize the time of travel and the loading time with regards to the path and extent of grasportaion and traffic flow should be evaluated to introduce effective factors in the decision-making (Campos et al., 2012).

Another model is investigated in terms of shortening the distance with the request and travel time constraints and the road damages (Shen et al., 2008) with regards to the fourth basis which is the number of cases that the request is not satisfied, the number of needed emergency units, the total number of covered requests, minimizing the risk and increasing the survival of people, decreasing the waiting time of injured people for help, the volume of traffic and capacity of havens based on the number of vehicle, request, the covered area, cost and time of travel has been created (Campos et al., 2012).

The locating and assigning in the transport of humanitarian logistics was proposed by minimizing the transportation time with regards to the series presenting, emergency requests and the budget and resource constraints to increase the lifetime of the patients (Edrissi, 2013). But based on the distribution, humanitarian logistics models have objectives such as cost which includes minimizing the travel costs, the distribution cost and distance whose space is proportional with the extent of supply (Liberatore et al., 2014). With the purpose of minimizing the transportation time and the distribution time of necessary goods and the service time some papers have been researched (Vitoriano et al., 2011). Satisfying the demand and the number of emergency units needed with regards to the number of vehicles, type of vehicles and the balance flow provided a basis in the distribution of the logistics models (Vitoriano et al., 2011). Locating and assigning can be investigated based on the cost, time and number factors. With the purpose of decreasing the travel cost, the distribution cost and shortening the distance for the factor of cost, factor of time, decreasing the transportation and distribution cost, the demand factor were investigated. The capacity of facilities is one of the main items in these problems with regards to the satisfaction of demand. Therefore issues such as the extent of stock and the resource flow and the number of injured are from this category (Davis et al., 2013). 


\section{Expression of the Model}

Distribution starts at a central supply point (CSP) which is a meeting point that receives resources permanently and prepare them for distribution. A discrete planning horizon is considered in short periods which are referred to as distribution periods. Demand and supply capacity are known in each period. In a location where is influenced by a disaster, individuals demands are classified with close proximity as accumulated demand points (ADPs). It is assumed that the total predicted capacity in CSP surpasses the ADPs in the total planning horizon.

In the beginning of each distribution period, temporary distribution centers (TDCs) are selected which relies on demand concentration and equipment capacity. Resources are allocated to TDCs from CSP and are distributed to ADPs from TDC. During the distribution period, the demands of some ADPS might be left unsatisfied. Exorbitant and returned demand suspends the order and should be satisfied in the next periods, which is conducted as satisfaction of late orders. In a period that supply accessibility of a particular type of resource in CSP is more than the total demand for the same resource, CSP can allocate the surplus quantity of resource to TDCs which are used in the next periods or for distributing from TDC or through transportation to a proximate TDC.

For expanding this model, $t(t \in \tau)$ is assumed as the period title and $\mathrm{k}$ is assumed as the resource type $k(k \in K)$ for distribution. CSP supply and demand capacities are predicted for periods in the beginning of T.

A complete list of model parameters and their initials are presented as follows,

\begin{tabular}{|c|c|}
\hline Initial & Description \\
\hline TDC & Temporary distribution center \\
\hline ADP & Accumulated demand point \\
\hline CSP & Central supply point \\
\hline \multicolumn{2}{|c|}{ Indexes } \\
\hline M & All of the potential indexed TDCs \\
\hline $\mathrm{N}$ & All of the potential ADPs indexed as $n$ \\
\hline $\mathrm{T}$ & All of the potential periods indexed as $t$ \\
\hline $\mathrm{K}$ & All of the relief resources indexed as $\mathrm{k}$ \\
\hline LV & All of the price levels indexed as lv \\
\hline $\mathrm{H}$ & All of the potential hubs indexed as $h$ \\
\hline $\mathrm{C}$ & All of the insurer companies indexed as c \\
\hline $\mathrm{S}$ & All of the scenarios indexed as $\mathrm{s}$ \\
\hline \multicolumn{2}{|c|}{ Parameters } \\
\hline $\mathrm{S}^{\mathrm{k}}$ & Space needed for storing each unit of the $\mathrm{k}$ type resource \\
\hline $\mathrm{L}_{\mathrm{t}}$ & Duration of the $t$ period in the planned distribution time $t$ \\
\hline $\mathrm{N}$ & Number of time periods \\
\hline $\mathrm{D}^{\mathrm{k}_{\mathrm{it}}}$ & Demand for a $\mathrm{k}$ type resource in ADPi in a time period $\mathrm{t}$ \\
\hline $\mathrm{GG}_{\mathrm{t}}^{\mathrm{k}}$ & Capacity of type $\mathrm{k}$ resource in CSP in a time period $\mathrm{t}$ \\
\hline $\mathrm{V}_{\mathrm{j}}$ & Capacity of TDCj \\
\hline $\mathrm{F}_{\mathrm{j}}$ & Fixed cost of operation of a TDCj \\
\hline$\tau_{j}^{0}$ & Travel time from CSP to TDCj \\
\hline$\tau_{j i}$ & Travel time from TDCj to ADPi \\
\hline $\mathrm{TC}^{\mathrm{k} 0}{ }_{\mathrm{j}}$ & Unit cost of transportation of a k type resource from CSP to TDCj \\
\hline
\end{tabular}


$C G_{j t l v}^{k} \quad$ Transportation unit cost of a $\mathrm{k}$ type resource from TDCm to TDCj

$b b_{l v j t}^{k} \quad$ Quantity of a k type resource allocated from CSP to TDCj selected in a t time period and fitting the price level lv

$T C^{k l}{ }_{m j} \quad$ Unit cost of transportation from a $\mathrm{k}$ type resource from TDCm to TDCj

$T C^{k E_{j i}} \quad$ Unit cost of transportation from a $\mathrm{k}$ type resource from TDCj to ADPi

$P_{i t l}^{k} \quad$ Satisfaction punishment unit cost of ADPi from a $\mathrm{k}$ type resource from time period 1 in a time period $\mathrm{t}$

B Large number

$c c_{i j t} \quad$ Special route formation cost

$p_{s} \quad$ Occurrence probability of scenario $\mathrm{S}$

$c y_{h} \quad$ Establishment cost of hub h

$i c_{j t c} \quad$ Cost of insurance coverage

BUDGET Total available budget

$\mathrm{H} \quad$ Preservation cost

$\emptyset_{(\theta)}^{-1} \quad$ Probability of relief resources accessibility

$D \quad$ Fuzzy lower margins of demand

$\bar{D}_{i t}^{k} \quad$ Fuzzy demand average

$\gamma \quad$ Weight of scenario effects on each other

$\mu \quad$ Weight of feasibility effects

$\theta \quad$ Demand satisfaction percent

$\operatorname{cap}_{h} \quad$ Capacity of hub h

$\quad l l_{k t} \quad \mathrm{~K}$ resource delivery time in period $\mathrm{t}$

Decision making variables

$\mathrm{y}_{\mathrm{it}} \quad$ A binary variable which when the $\mathrm{j}$ facility is selected as TDC in period $\mathrm{t}$ it equals to 1 , otherwise, it is 0

$\mathrm{x}_{\mathrm{jit}} \quad$ A binary variable which if ADPi receives a resource from TDCk in $\mathrm{t}$ period, it is equal to 1

$X X_{i j t} \quad$ A binary variable as special route which if ADPi receives a resource from TDC in $\mathrm{t}$ period and delivery length surpases the period length, it is equal to one

$\mathrm{r}_{\mathrm{jt}}^{\mathrm{k}} \quad$ Quantity of a $\mathrm{k}$ type resource allocated from CSP to TDCj selected in a t period

$G_{j t l v}^{k} \quad$ Quantity of a k type resource allocated from CSP to TDCj selected in a $t$ period in the price level of lv

$q^{k}$ mjts $\quad$ Quantity of a k type resource transported from TDCm from the $\mathrm{t}-1$ period to TDCj from the $\mathrm{t}$ time period in the s scenario

$a_{j t}^{k} \quad$ Quantity of a $\mathrm{k}$ type resource in TDCj in the time period $\mathrm{t}$

$=r_{j t}^{k}+\sum_{m \in M} q_{m j t}^{k}$

$z_{j i t}^{k} \quad$ Quantity of a k type resource supplied from TDCj in t time period for satisfying demands in ADPi produced within the same period

$w_{j i t l}^{k} \quad$ Total $\mathrm{k}$ type resource satisfied by TDCj in t time period for compliance with the suspended demand from the period 1 in ADPi which $l \epsilon \tau, l<t$

$b_{j t s}^{k} \quad$ Total quantity of a $\mathrm{k}$ type resource for all ADPs from TDCj in t period in s scenario

$=\sum_{i}\left(z_{j i t}^{k}+\sum_{l, l<\tau} w_{j i t l}^{k}\right)$

$\delta_{j t s}^{k} \quad$ Deviation amount for total quantity of a distributed $\mathrm{k}$ type resource for all ADPs from TDC in t time period in s scenario

$\Delta_{j t s}^{k} \quad$ Robust linearizer variable

$\theta \theta_{j t s}^{k} \quad$ Robust linearizer variable

$Y Y_{h} \quad$ If hub $\mathrm{h}$ is formed, it equals to 1 , otherwise it is zero

$I_{j t c} \quad$ If TDCj is under insurance coverage of c insurer in t time period, this variable is 1 , otherwise it is zero

$Y L_{l v j t}^{k} \quad$ If lv price level for the quantity of a k type resource allocated from CSP to TDCj selected in a t time period is active, it equals to 1 , otherwise it is zero 
The proposed model is presented below:

$f_{1}: \min$

$\sum_{j} \sum_{t} F_{j} y_{j t}+\sum_{k} \sum_{j} \sum_{t} T C_{j}^{k o} r_{j t}^{k}+\sum_{k} \sum_{m} \sum_{j} \sum_{t} \sum_{s} T C_{m j}^{K I} q k m j t s$

$+\sum_{k} \sum_{j} \sum_{i} \sum_{t} T C_{j i}^{K E}\left[Z_{j i t}^{k}+\sum_{l, l<t} W_{j i t l}^{k}\right]+\sum_{k} \sum_{j} \sum_{i} \sum_{t} \sum_{l} P_{i t l}^{K} W_{j i t l}^{k}$

$+\sum_{i} \sum_{j} \sum_{t} c c_{i j t} X X_{i j t}+\sum_{h} c y_{h} Y Y_{h}+\sum_{j} \sum_{t} \sum_{c} i c_{j t c} I_{j t c}+\sum_{j} \sum_{t} \sum_{k} \sum_{l v} C G_{j t l v}^{k} G_{j t l v}^{k}$

$\sum_{j} \sum_{t} \sum_{s} \sum_{m} \sum_{k} p_{s}\left(b_{j t s}^{k}+q_{j m t s}^{k}\right)+\gamma\left(\sum_{s} p_{s}\left(\sum_{j} \sum_{t} \sum_{m} \sum_{k}\left(b_{j t s}^{k}+q_{j m t s}^{k}\right)-\sum_{s^{\prime}} p_{s^{\prime}}\left(\sum_{j} \sum_{t} \sum_{m} \sum_{k}\left(b_{j t s}^{k}+\right.\right.\right.\right.$ $\left.\left.q_{j m t s}^{k}\right)+2 \theta \theta_{j t s}^{k}\right)+\mu \sum_{i} \sum_{j} \sum_{t} \sum_{s} \sum_{k} p_{s}\left(\delta_{j t s}^{k}+2 \Delta_{j t s}^{k}\right)$

$f_{2}$ : Maxmize

$\sum_{j} \sum_{i} \sum_{t} \sum_{l} \sum_{k} \frac{Z_{j i t}^{k}}{W_{j i t l}^{k}}$

$f_{3}$ : Minimize

$\sum_{j} \sum_{i} \sum_{t} \sum_{l} \sum_{k}\left(D_{j i t l}^{k} \frac{l l_{k t}}{L_{t}}-W_{j i t l}^{k}-\frac{l l_{k t}}{L_{t}} Z_{j i t}^{k}\right)$

$\sum_{i \in N} X_{j i t}-B y_{j t} \leq 0 \quad \forall j \epsilon M$, and $t \epsilon \tau$

$\sum_{i \in N} X X_{i j t}-B y_{j t} \leq 0 \quad \forall j \in M$, and $t \epsilon \tau$

$y_{j t} \leq \sum_{c} I_{j t c} \quad \forall j \in M, \forall t \in \tau$

$\sum_{c} I_{j t c} \leq 1 \quad \forall j \in M, \forall t \in \tau$

$r_{j t}^{k} \leq \sum_{l v} G_{j t l v}^{k} \forall j \in M, \forall t \in \tau, \forall k \in K$

$G_{j t l v}^{k} \leq\left(b b_{l v j t}^{k}-b b_{l v-1 j t}^{k}\right) Y L_{l v j t}^{k} \quad \forall j \in M, \forall t \in \tau, \forall k \in K, \forall l v \in L v$

$G_{j t l v}^{k} \geq\left(b b_{l v j t}^{k}-b b_{l v-1 j t}^{k}\right) Y L_{l v+1 j t}^{k} \quad \forall j \in M, \forall t \in \tau, \forall k \in K, \forall l v \in L v$

$\sum_{j \in M} r_{j t}^{k} \leq G G_{t}^{k} \quad \forall k \in K$, and $t \in \tau$

$\sum_{k \in K} S^{k} a_{j t}^{k} \leq V_{j} y_{j t} \quad \forall j \in M$, and $t \in \tau$

$b_{j t s}^{k}+\sum_{m \in M} q_{j m(t+1) s}^{k}+\delta_{j t s}^{k}=a_{j t}^{k} \quad \forall j \in M, k \in K, \forall s \in S$, and $t \epsilon \tau$

$-\sum_{j} \sum_{t} \sum_{k} \Delta_{j t s}^{k}-\sum_{j} \sum_{t} \sum_{k} \delta_{j t s}^{k} \leq 0 \forall s \in S$

$-\sum_{j} \sum_{t} \sum_{k} \theta \theta_{j t s}^{k}-\sum_{j} \sum_{t} \sum_{k} \sum_{m}\left(b_{j t s}^{k}+q_{j m t s}^{k}\right)+\sum_{s^{\prime}} p_{s^{\prime}} \sum_{j} \sum_{t} \sum_{k} \sum_{m}\left(b_{j t s}^{k}+q_{j m t s}^{k}\right) \leq 0 \forall s \in S$

$Z_{j i t}^{k} \leq B X_{i j t} \quad \forall k \in K, j \in M, i \in N$, and $t \in \tau$

$W_{j i t l}^{k} \leq B X_{i j t} \quad \forall k \in K, j \in M, i \in N, t \in \tau$, and $l \in \tau, l<t$

$\sum_{j} W_{j i t l}^{k} \leq \sum_{h} \operatorname{cap}_{h} Y Y_{h} \quad \forall k \in K, i \in N, t \in \tau, \forall h \in H$, and $l \epsilon \tau, l<t$

$\tau_{j i} X_{i j t}-M X X_{i j t} \leq L_{t} \quad \forall i \in N, j \in M$, and $t \in \tau$

$\emptyset_{(\theta)}^{-1}\left(\sum_{j \in M}\left(Z_{j i t}^{k}+\sum_{t \in \tau, t>l} W_{j i t l}^{k}\right)\right)=D_{i l}^{k}-\bar{D}_{i l}^{k} \forall k \in K, \quad i \in N$, and $l \epsilon \tau$ 


$$
\begin{aligned}
& \sum_{j \in M}\left(Z_{j i t}^{k}+\sum_{t \in \tau, t>l} W_{j i t l}^{k}\right)=(1-2 \theta)\left(D_{i l}^{k}-D\right)+2 \theta D_{i l}^{k} \quad \forall k \in K, i \in N, \quad \text { and } l \epsilon \tau \\
& \sum_{j} \sum_{t} F_{j} y_{j t}+\sum_{k} \sum_{j} \sum_{t} T C_{j}^{k o} r_{j t}^{k}+\sum_{k} \sum_{m} \sum_{j} \sum_{t} \sum_{s} T C_{m j}^{K I} q k m j t s \\
& +\sum_{k} \quad \sum_{j} \sum_{i} \sum_{t} T C_{j i}^{K E}\left[Z_{j i t}^{k}+\sum_{l, l<t} W_{j i t l}^{k}\right]+\sum_{k} \quad \sum_{j} \sum_{i} \sum_{t} \sum_{l} P_{i t l}^{K} W_{j i t l}^{k} \\
& +\sum_{i} \sum_{j} \sum_{t} c c_{i j t} X X_{i j t}+\sum_{h} c y_{h} Y Y_{h}+\sum_{j} \sum_{t} \sum_{c} i c_{j t c} I_{j t c}+\sum_{j} \sum_{t} \sum_{k} \sum_{l v} C G_{j t l v}^{k} G_{j t t v}^{k} \leq \text { BUDGET } \\
& W_{j i t l}^{k} \geq \frac{H z_{j i t}^{k}}{P_{i t t}^{K}+H} \forall k \in K, j \in M, i \in N, t \in \tau \text {, and } l \in \tau, l<t \\
& q_{m j t s}^{k}=0 \quad \forall k \in K, j, m \in M, \forall s \in S \text {, and } t=1, N+1 \\
& y_{j t} \in\{0,1\} \quad \forall j \in M \text {, and } t \in \tau \\
& X_{i j t} \in\{0,1\} \quad \forall j \in N, j \in M \text {, and } t \in \tau \\
& r_{j t}^{k}, q_{m j t s}^{k}, Z_{j i t}^{k} \geq 0 \quad \forall i \in N, j, m \in M, k \in K, \forall s \in S \text {, and } t \in \tau \\
& W_{j i t l}^{k} \geq 0 \quad \forall i \in N, j \in M, k \in K, t \in \tau \text {, and } l \in \tau, l<t
\end{aligned}
$$

Objective function (1a) minimizes the loss or logistic costs of compensative supply. This matter includes fixed costs, transportation and resource supply costs, distribution and transportation between TDCs, delay punishment costs, insurance costs, hub establishment and purchased price level with regard to gradual discount. On the other hand, the robust part indicates the Mulvey Robust of the problem for available resources in TDCs. Deviation from the feasibility space and the impact of other scenarios on each other are taken as a factor of making the model robust (Mulvey et al., 1995). The objective function (1b) tries to increase the chance of demand satisfaction with no time delays. The objective function (1c) tries to increase the budget and the amount of demand response through lowering the order point. Eq. (2a) makes sure that ADP-i is allocated to TDC-c in $t$ period. Eq. (2a) makes sure that a special route is dedicated to TDC-j in relation to ADP-i in $t$ time period. Eq. (3a) allocates a TDC-j whenever one is generated. Eq. (3b) makes sure only one TDC is allocated to the insurer company. Eq. (4a) classifies the quantity of a $k$ type resource allocated from CSP to TDCj selected in a $t$ time period in various levels based on discount. Eq. (4b) and Eq. (4c) activate a price level for any demanded amount. Eq. (5) makes sure that the allocation of resources from CSP to TDC would not surpass the available amount of CSP during time period. Eq. (6) is associated with the capacity limitation of TDC. Eq. (7) is the limitation of flow preservation in TDCs which should make sure about the total surplus amounts that should be transported so that TDCs could operate in a tandem cycle. Eq. (8) and Eq. (9) are to make the model robust. Eq. (10) and Eq. (11) make sure about resource distribution between the allocated couples of TDC and ADP. The model is generated for suspended demand satisfaction in time period $t$. Suspended demand is in a demanded ADP-i which is not satisfied in time period $1(1<t)$. This presentation is determined from a satisfier suspended demand in Eq. (11). According to Eq. (12), all $k$-type resources satisfied by TDCj at $t$ time period should be supplied from $h$ hubs, so that it complies with the suspended demand from period 1. Eq. (13) makes sure that the necessary movement time for serving ADP-i by TDC-j at $t$ period does not surpass the period time. If this time surpasses the period time, a strategic decision on formation of a special route will be made.

Eq. (14a) verifies the satisfactory state of all demands in ADPs considering the chance of being satisfied by distributed relief commodities until the end of planning horizon. Eq. (14b) verifies the satisfactory state of all fuzzy demands with a maximum confidence level of 50 percent in ADPs until the end of planning horizon. The presented model is analyzed once with Eq. (14a) and another time with limitation Eq. (14b). The minimum response accurate for both problems is the final response of the model. Through using the analysis of these two problems, a problem which needs the decision maker planning type and needs to utilize this model is selected. Eq. (15) shows the budget limitation. Eq. (16) shows the minimum delayed orders. Eqs. (17-21) are system limitations. 
In this model, uncertainty of demand satisfaction and the satisfaction method were is investigated (Ke \& Liu, 2007).

\section{Solution Method}

\section{1. $\varepsilon$-Constraint Method}

This method can transform a multi-objective problem into a single-objective one with additional constraints, where the objective with the highest priority is maintained as the main objective function (MOF) and the others are transformed into the constraints. For instance, application of the $\varepsilon$-Constraint Method for the given problem can be written through Eq. (22), as follows,

$$
\begin{aligned}
& \min f_{1}(X) \\
& x \in X \\
& f_{2}(X) \leq \varepsilon_{2} \\
& \cdots \\
& f_{n}(X) \leq \varepsilon_{n}
\end{aligned}
$$

In the proposed problem, we have:

$$
\begin{aligned}
& \min f=f_{1} \\
& f_{2}(X) \leq \varepsilon_{2} \\
& f_{3}(X) \leq \varepsilon_{3}
\end{aligned}
$$

As can be seen, $f_{1}$ has been remained in the MOF, representing the total cost, and $f_{2}$ and $f_{3}$ have been transformed into the constraints. Briefly, the procedure of the mentioned $\varepsilon$-Constraint Method is as bellows:

1) Choose one of the objective functions as MOF.

2) Consider three break points for the objectives $f_{2}$ and $\mathrm{f} 3$, so that nine Pareto points can be generated for each problem. Notice, choose

3) Solve the problem with its MOF, and report the objective function values to determine Pareto front.

\section{Table 1}

Different vector choice in each break point

\begin{tabular}{ccc}
\hline \multirow{2}{*}{ Break Point } & \multicolumn{2}{c}{ Constraint vector choice } \\
\cline { 2 - 3 } & $\varepsilon_{2}$ & $\varepsilon_{3}$ \\
\hline 1 & $3.589411 \mathrm{E}+9 *$ & $771352.410^{*}$ \\
2 & $3.8 \mathrm{E}+9$ & 700000 \\
3 & $4 \mathrm{E}+9$ & 600000 \\
\hline
\end{tabular}

*Obtained by solving single-objective problem

\section{Metaheuristic approach}

The proposed exact method is not capable of solving large scale problems in a reasonable time. Thus, in order to solve the problem in the least time possible a Non-dominated sorting Genetic Algorithm (NSGA II) is used. In this section, the proposed NSGA II algorithm is introduced and its elements are described. Then, the performance proposed algorithm is compared with the results of $\varepsilon$-Constraint and it is validated to examine whether the proposed metaheuristic approach is efficient. Finally, a large scale sample is solved and the corresponding results and Pareto fronts are presented. 


\section{$4.1 \quad$ Elements of Genetic algorithm}

Chromosome: here, two chromosome are defined to form the solution space. A binary chromosome is used with $J \times T$ cells where $J$ and $T$ are the number of facilities and time periods. Obviously, if facility $j$ is established as a temporary distribution center in period $t$, the corresponding cell in the chromosome would be one, otherwise zero. In addition, a second binary chromosome is also defined with $\mathrm{I} \times \mathrm{J} \times \mathrm{T}$ cells. So, if accumulated demand point $i$ receives a resource from temporary distribution center $j$ at $t$ period, the related cell in chromosome is one, otherwise zero. Fig. 1 represents the applied chromosome for NSGA II algorithm.
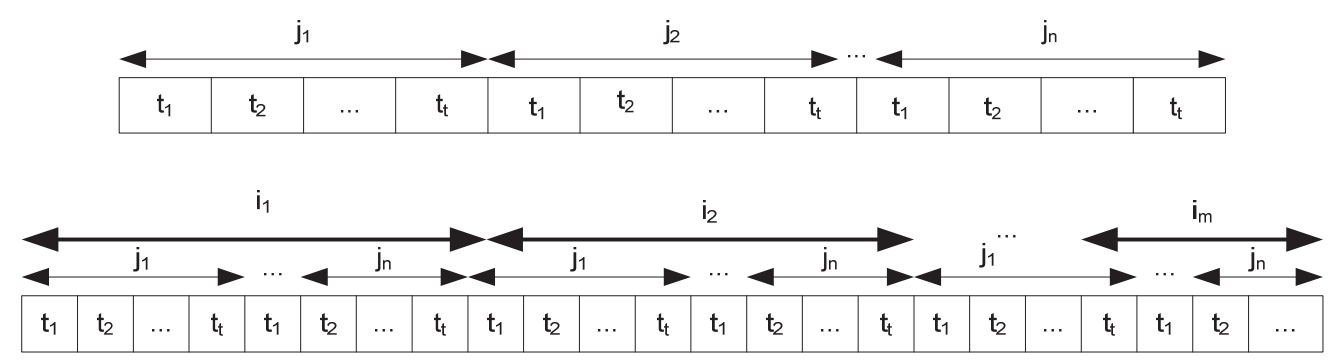

Fig. 1. Applied chromosome for NSGA II algorithm

Initial population: A group of chromosome generates the initial population. In this research, the initial population is considered equal to 300 and they are generated randomly.

Fitness function: the objective functions of the mathematical model is considered as fitness function for NSGA II algorithm.

Crossover operator: One-point crossover is used. A cell is selected randomly and the first part of the first parent and the second part of the second parent form a new chromosome as an offspring.

Parent 1

\begin{tabular}{|c|c|c|c|c|c|c|c|c|c|c|c|}
\hline 1 & 0 & 0 & 0 & 0 & 1 & 1 & 0 & 1 & 1 & 0 & 1 \\
\hline \multicolumn{12}{|c|}{ Parent 2} \\
\hline 0 & 0 & 1 & 0 & 1 & 0 & 1 & 0 & 0 & 0 & 0 & 1 \\
\hline \multicolumn{12}{|c|}{ Offspring } \\
\hline 1 & 0 & 0 & 0 & 0 & 0 & 1 & 0 & 0 & 0 & 0 & 1 \\
\hline
\end{tabular}

Fig. 2. Crossover operator

Mutation operator: A cell is selected randomly and the value of the cell is reversed.

\begin{tabular}{|l|l|l|l|l|l|l|l|l|l|l|l|}
\hline 1 & 0 & 0 & 0 & 0 & 1 & 1 & 0 & 1 & 1 & 0 & 0 \\
\hline 1 & 0 & 0 & 0 & 0 & 1 & 1 & 0 & 1 & 1 & 0 & 1 \\
\hline
\end{tabular}

Fig. 3. Crossover operator

Stopping criterion: if the solution quality does not improve in last 50 iteration the algorithm stops and the best obtain solution is reported.

\subsection{Validation}

To evaluate the performance of the proposed algorithm, a sample instance is solved and compared with the results of the sample solving exact method. For this propose, a random instance in small size (see Table 3) is generated and solved with both approaches and the results are presented. As far as the problem is investigated with multi objective function, to make a comparison between exact and 
metaheuristic approaches and to examine whether or not the proposed metaheuristic algorithm is efficient, some criteria are needed. In this research, criteria such as $\mathrm{MID}^{1}, \mathrm{SM}^{2}$ and $\mathrm{DM}^{3}$ has been utilized (Zitzler et al., 2000). In Table 2, these criteria are calculated and shown. As it is clear in the Table, the proposed NSGA II is performing very closely to the exact method. Although there are some differences between two approaches in all three criteria, they are nominal and negligible. Note that if MID and SM are more or DM is less, these are desirable. Therefore, these criteria cannot be transformed to one single criteria $(\mathrm{R})$ unless their direction becomes the same. By weighing these three criteria equally and making their directions in the same way, criterion $\mathrm{R}$ is calculated which shows an overall efficiency of the algorithm. The more the value of $\mathrm{R}$ is, the more efficient the algorithm is. As a result, the proposed NSGA II algorithm is efficient and finds near optimal solution.

\section{Table 2}

Validation of proposed NSGA II

\begin{tabular}{ccccc}
\hline Approach / Index & MID & SM & DM & R \\
\hline E-constraint & 0.49 & 0.93 & 1.32 & 1.47 \\
NSGA II & 0.53 & 0.95 & 1.19 & 1.37 \\
\hline
\end{tabular}

Also, the Pareto fronts for each pairs of objective functions are presented in Fig. 4. As it is evident, NSGA II algorithms properly finds the Pareto solution often as well as the exact method.

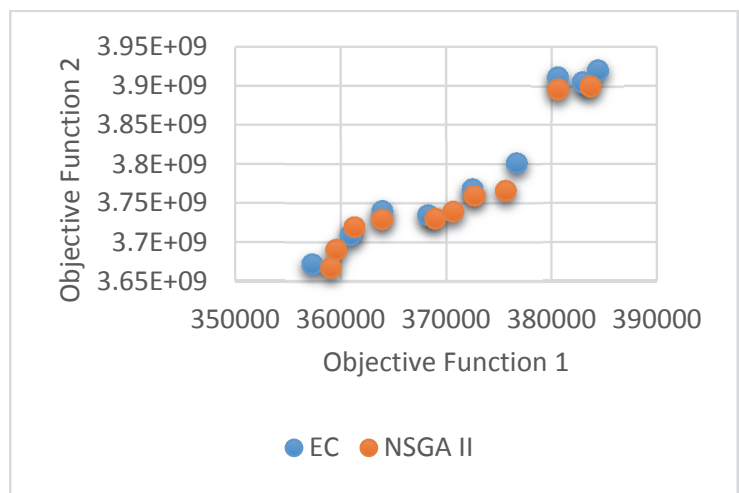

a) Pareto front derived from $1^{\text {st }}$ and $2^{\text {nd }}$ objectives

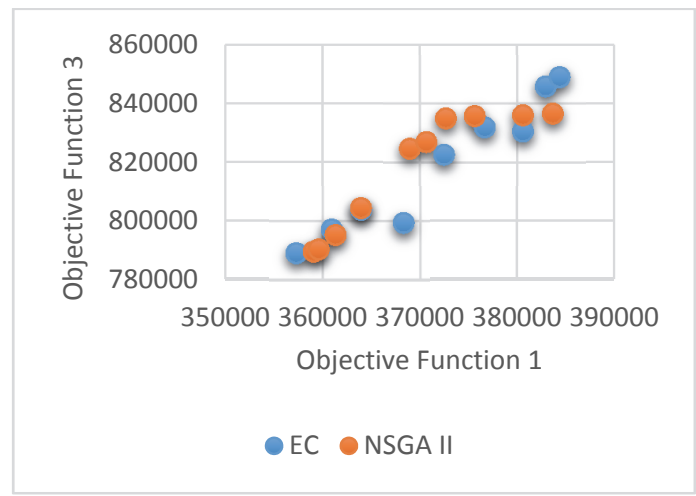

b) Pareto front derived from $1^{\text {st }}$ and $3^{\text {rd }}$ objectives

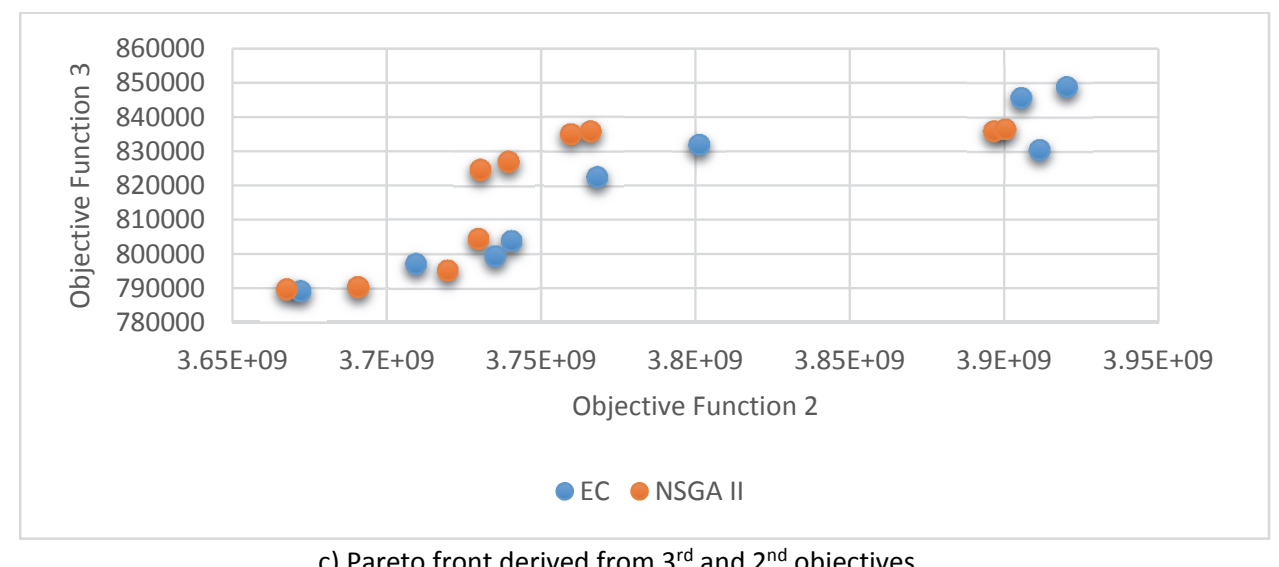

Fig. 4. Pareto front derived from objectives

\footnotetext{
${ }^{1}$ Mean Ideal Distance

2 Spacing Metric

${ }^{3}$ Diversification Metric
} 


\subsection{Solving Large Scale samples}

Since the proposed NSGA II has appropriate performance therefore, it can be used to solve large-scale problems where the exact method is not able to solve them in normal time. So, a large-scale sample instance (see Table 3) is solved and the results are shown. By solving this sample, 19 Pareto solutions have been reached. The values of the objective function for each of Pareto solutions are presented in Fig. 5.

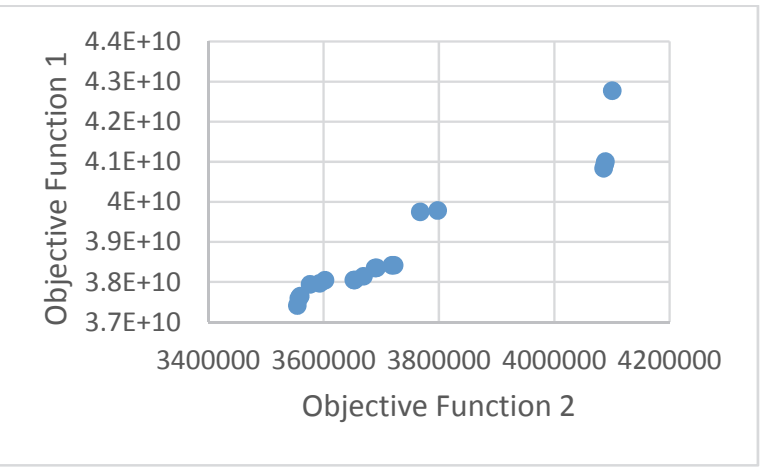

a) Pareto front for objective functions 1 and 2

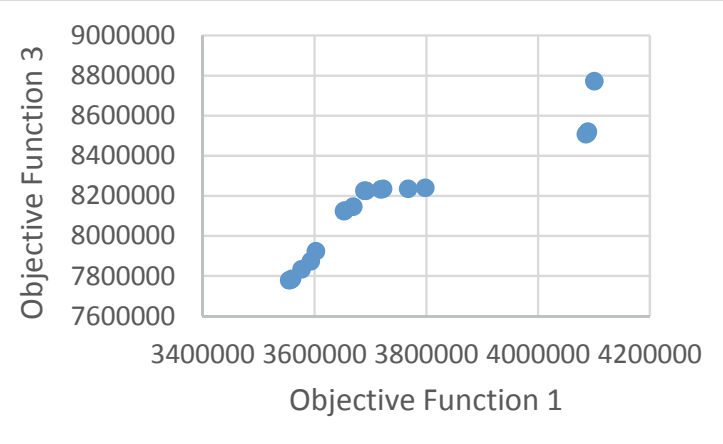

b) Pareto front for objective functions 1 and 3

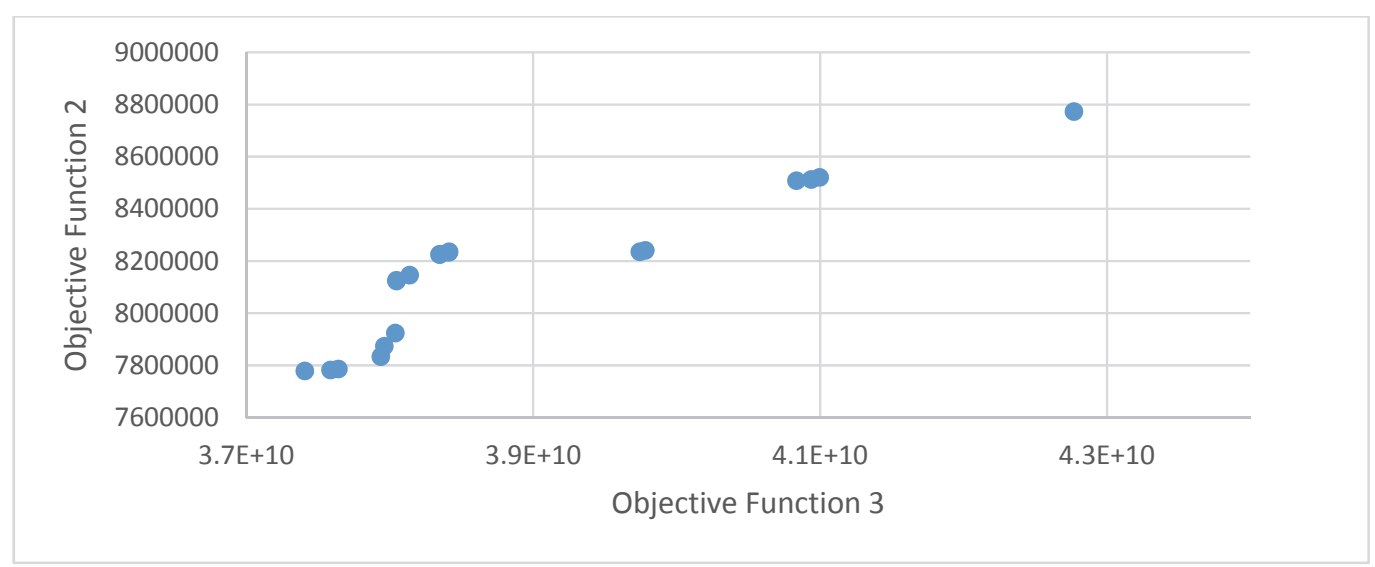

c) Pareto front for objective functions 2 and 3

Fig. 5. Pareto front for objective functions obtained by NSGA-II algorithm

\subsection{Results analysis}

A Sensitivity analysis were conducted on the presented model, so that its reliability could be assessed. Therefore, the sensitivity analysis is done by using the large-sized problem data defined in Table 3 .

We solve all the problems using the proposed NSGA-II and report the best Pareto solutions.

\section{Table 3}

Model's data in small and large size

\begin{tabular}{ccc}
\hline & Points number and different facilities & Large sized Instance \\
\hline Sets & Small sized instance & 8 \\
M & 4 & 12 \\
N & 6 & 8 \\
T & 4 & 4 \\
K & 2 & 6 \\
LV & 3 & 4 \\
H & 2 & 6 \\
C & 3 & 6 \\
S & 3 & \\
\hline
\end{tabular}


As we can observe as $\mu, P^{k}{ }_{i t l}, \theta, \bar{D}_{i t}^{k}, \emptyset_{(\theta)}^{-1}, L_{t}$ and $\gamma$ parameters in the problem are reduced and increased the sensitivity levels of problems 1 and 2 are studied. Problem one is solved according to Eq. (14a) and problem 2 is solved according to Eq. (14b). It is worthy to say the model were analyzed through the GAMS and Baron Solver software in 1000 seconds. As it is shown in the Fig. 6, objective 1 in problem 1 decreases as $L_{t}$ elevates. Except for the 20 percent increase range where compared to the former point, i.e. the 10 percent increase range, it does not change. One of its other noteworthy points is that as this parameter increases, the objective 1 is reduced until it stops in point 1.2. As the period lengthens, demand satisfaction is more feasible in the same period and the number of delayed orders are decreased, therefore less fines are generated. On the other hand, the necessary facilities for forming a special route in order to achieve the standard time is not needed. Therefore, costs are saved and this matter continues until all demands are satisfied without delay. Objective 2 does not change in problem 1 for $\mathrm{L}_{\mathrm{t}}$ changes. Objective 3 decreases in problem one where $L_{t}$ increases. This reduction of objective 3 has a relatively constant slope. As the length of the period when the amount of satisfied demands with no delays increases, the objective function decreases.

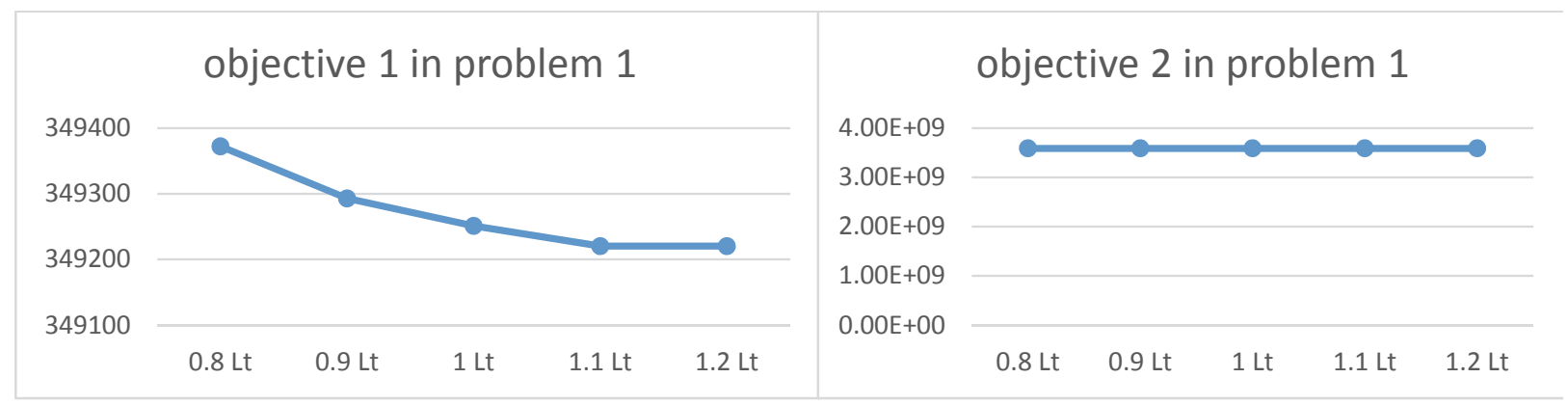

a) $L_{t}$ changes effects on the first objective

b) $L_{t}$ changes effects on the second objective

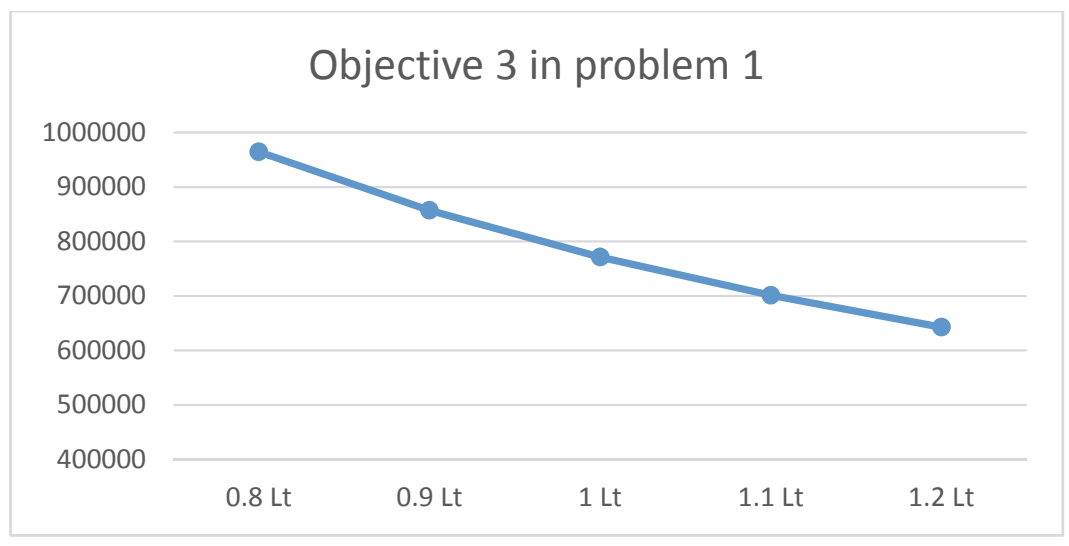

c) $L_{t}$ changes effects on the third objective

Fig. 6. $\mathrm{L}_{\mathrm{t}}$ changes effects on the objectives in problem 1

As it is indicated in Fig. 7, objective 1 decreases in problem 2 as $L_{t}$ increases. These changes are considerable for a 20 percent decrease. In other words, for a 20 percent decrease of this parameter, the objective function increases, enormously. One of the other noteworthy points is that as this parameter increases, the change range of objective 1 has a constant slope from point $0.9 \mathrm{on}$. With the increase of the period length, demand satisfaction is more feasible in the same period and the delayed orders are reduced, therefore less fines are generated. On the other hand, the necessary facilities for forming a 
special route in order to achieve the standard time is not needed. Therefore, costs are saved and this matter continues until all demands are satisfied without delay. Reduction level is higher before the deflection point, as it prevents the establishment of necessary facilities for special route and costs are more reduced. Objective 2 does not change in the problem 2 for $L_{t}$ changes. Objective 3 decreases in problem 2 where $L_{t}$ increases. This reduction of objective 3 has a relatively constant slope. As the length of the period when the amount of satisfied demands with no delays increases, the objective function decreases.

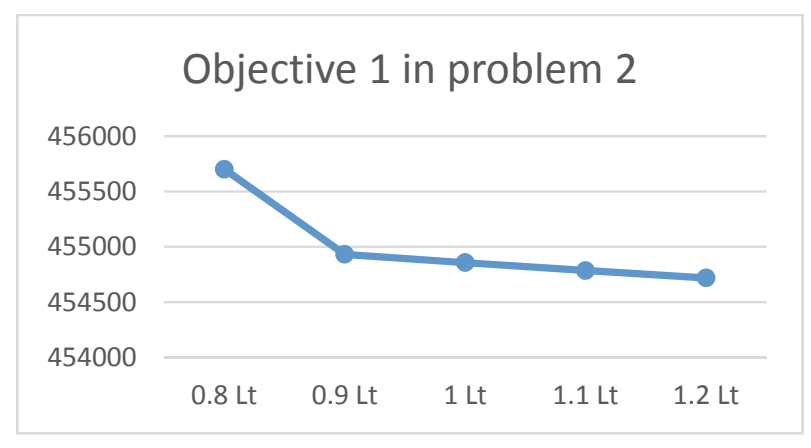

a) $L_{t}$ changes effects on the first objective

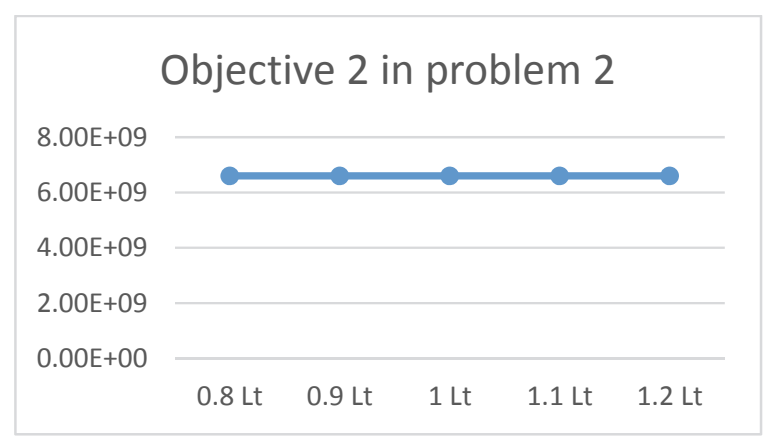

b) $L_{t}$ changes effects on the second objective

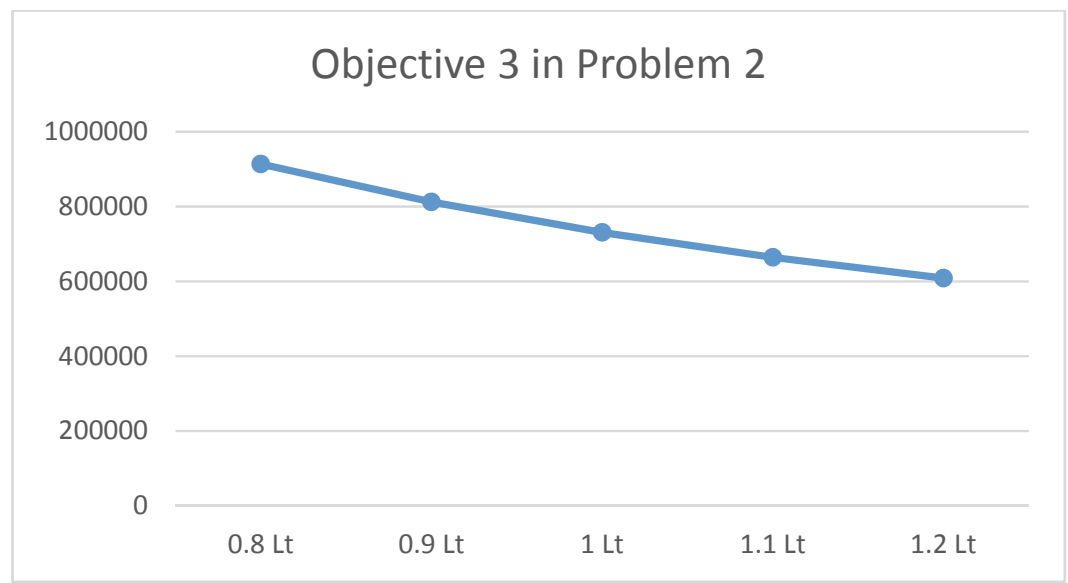

c) $L_{t}$ changes effects on the third objective

Fig. 7. $L_{t}$ changes effects on the objectives in problem 2

As it is indicated in Fig. 8, objective 1 decreases in problem one as $\emptyset_{(\theta)}^{-1}$ increases, where this reduction of objective 1 is in a relatively constant slope. With the increase of transported relief material accessibility, more material is transported and therefore, costs are saved. Objective 2 decreases in problem 1 as $\emptyset_{(\theta)}^{-1}$ increases. This reduction of objective 1 is with a relatively constant slope. As this parameter increases, there is a higher chance of demand satisfaction in the first run when the demand should be met, because if the unsatisfied demands are piled up, this variable will decrease more. Objective 3 increases in problem 1 as $\emptyset_{(\theta)}^{-1}$ increases. The increase of objective 3 is with a constant slope. Although it becomes more steep in the reduction ranges. As this parameter increases, the demand satisfaction in the first run decreases more. Thus, the amount of the objective function increases. 


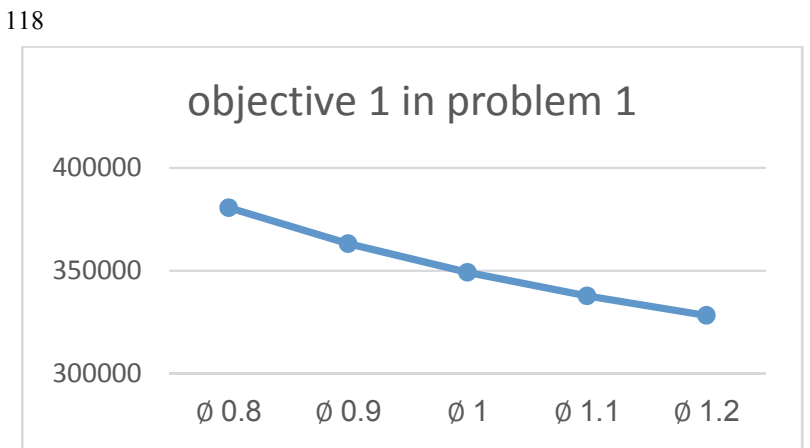

a) $\emptyset_{(\theta)}^{-1}$ changes effects on the first objective

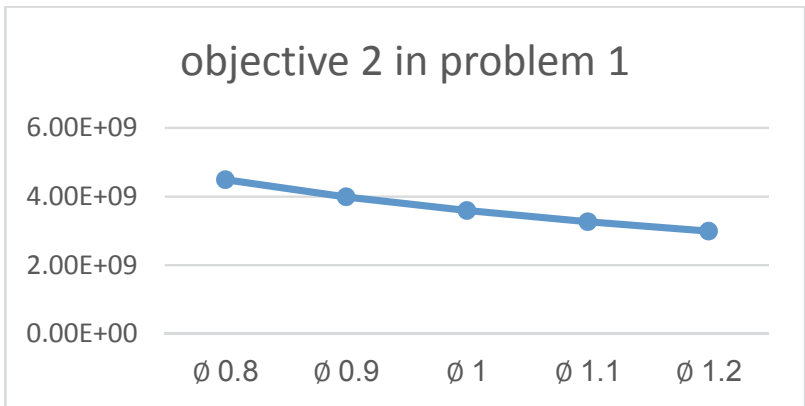

b) $\emptyset_{(\theta)}^{-1}$ changes effects on the second objective

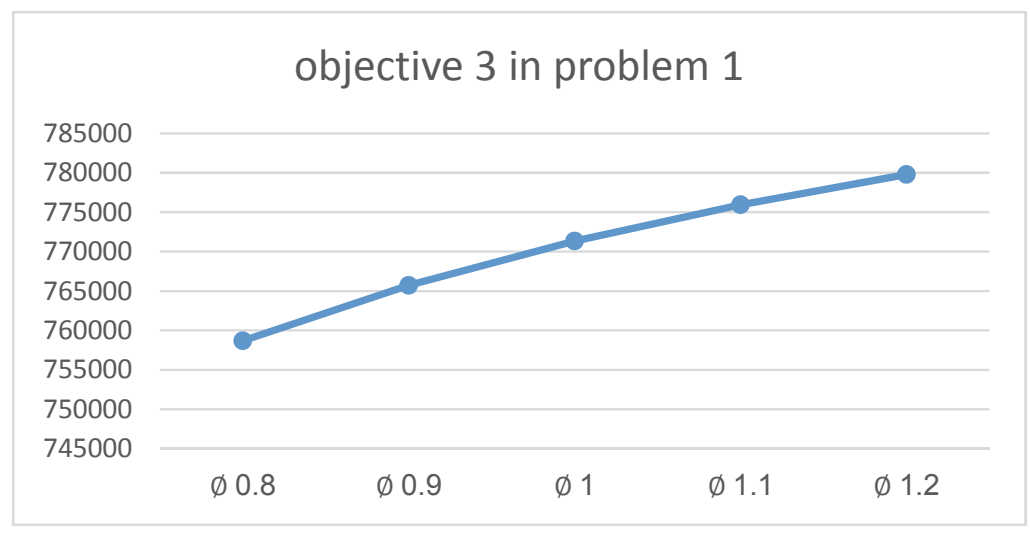

c) $\emptyset_{(\theta)}^{-1}$ changes effects on the third objective

Fig. 8. $\emptyset_{(\boldsymbol{\theta})}^{-1}$ changes effects on the objectives in problem 1

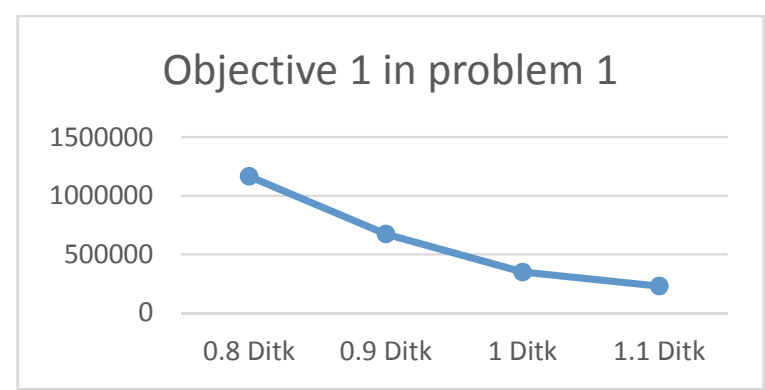

a) $\overline{\boldsymbol{D}}_{i t}^{k}$ changes effects on the first objective

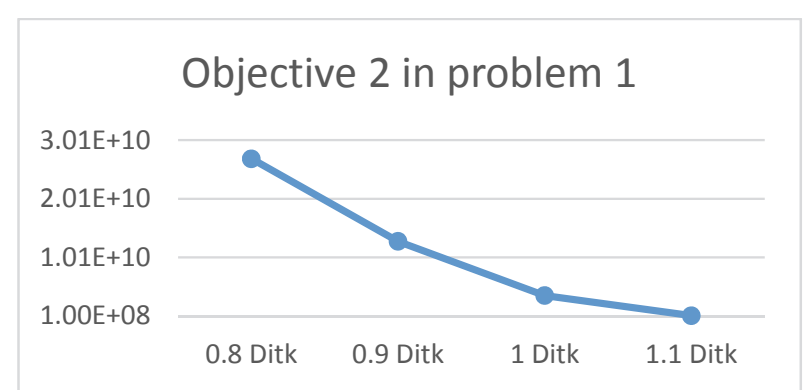

b) $\overline{\boldsymbol{D}}_{i t}^{k}$ changes effects on the second objective

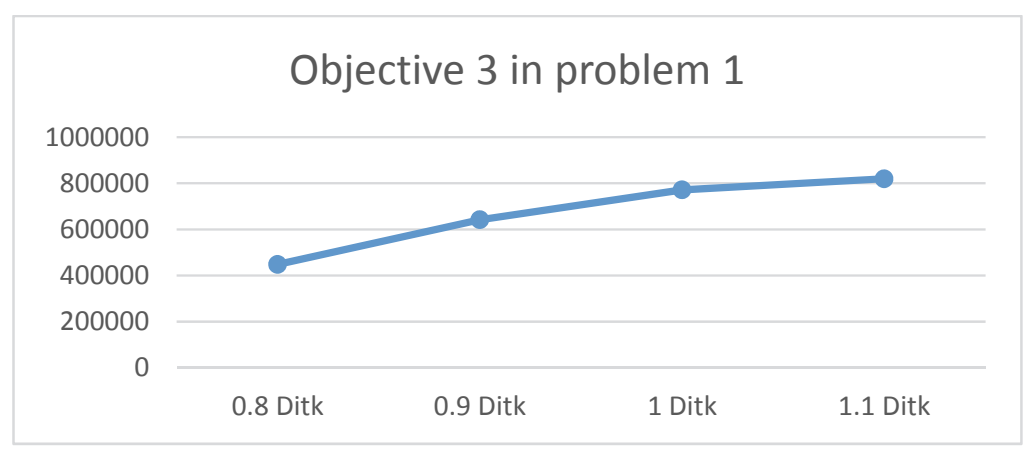

c) $\overline{\boldsymbol{D}}_{i t}^{k}$ changes effects on the third objective

Fig. 9. $\bar{D}_{i t}^{k}$ changes effects on the objectives in problem 1 
As it is indicated from the Fig. 9, objective 1 decreases in problem 1 as $\bar{D}_{i t}^{k}$ increases. Except for the 20 percent increase range where the problem becomes invalid. One of the other noteworthy points is that for increasing this parameter, the objective 1 change amount is gradually reduced and it finally stops in point 1.2. With the reduction of demands, less satisfaction is made and thus, cost is reduced. Objective 2 decreases in problem 1 as $\bar{D}_{i t}^{k}$ increases. Except for the 20 percent increase range where the problem becomes invalid. One of the other noteworthy points is that for increasing this parameter, the objective 1 change amount is gradually reduced and it finally stops in point 1.2. With demand reduction, the chance of demand satisfaction is reduced as well demand satisfaction is reduced because the time for demand satisfaction for the first time to turn into a delayed is increased. Objective 3 increases in problem 1 as $\bar{D}_{i t}^{k}$ increases. Except for the 20 percent increase range where the problem becomes invalid. One of the other noteworthy points is that for increasing this parameter, the objective 1 change amount is gradually reduced and it finally stops in point 1.2. As demand reduces, because of more reduction in demand satisfaction in the first run variable, the objective function increases. As it is indicated in the Fig. 10, objective 1 increases in problem two as $\theta$ increases. This increase of objective 1 is in a relatively constant slope. As the amount of demands needing satisfaction increases, costs elevate as well. Objective 2 increases in problem 2 as $\theta$ increases. This increase of objective 1 is with a relatively constant slope. With the increase of demand, the level of demand satisfaction increases and the level of this increase is more in the variable that leads to demand satisfaction in the first order run, therefore, satisfaction chance increases. Objective 3 reduces in problem 2 as $\theta$ increases. This reduction of objective 3 is with a relatively constant slope. As this parameter increases, the demand of each period is more satisfied within the same period and the objective function reduces.

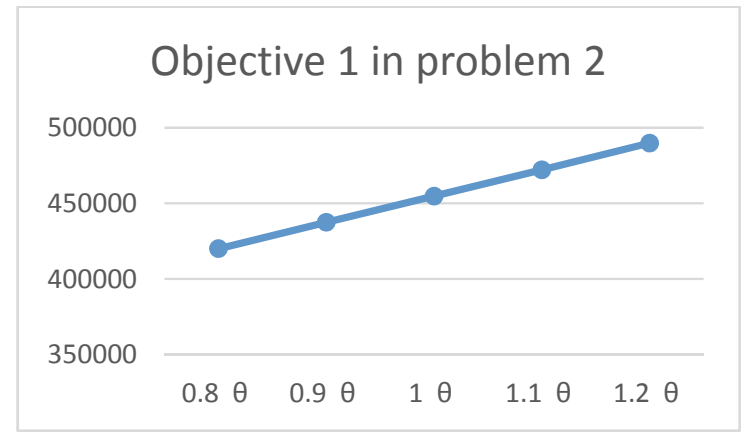

a) $\boldsymbol{\theta}$ changes effects in the first objective

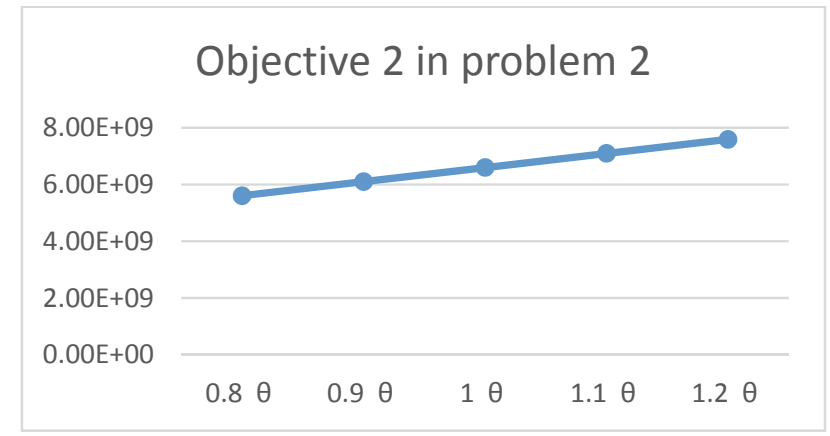

b) $\boldsymbol{\theta}$ changes effects in the second objective

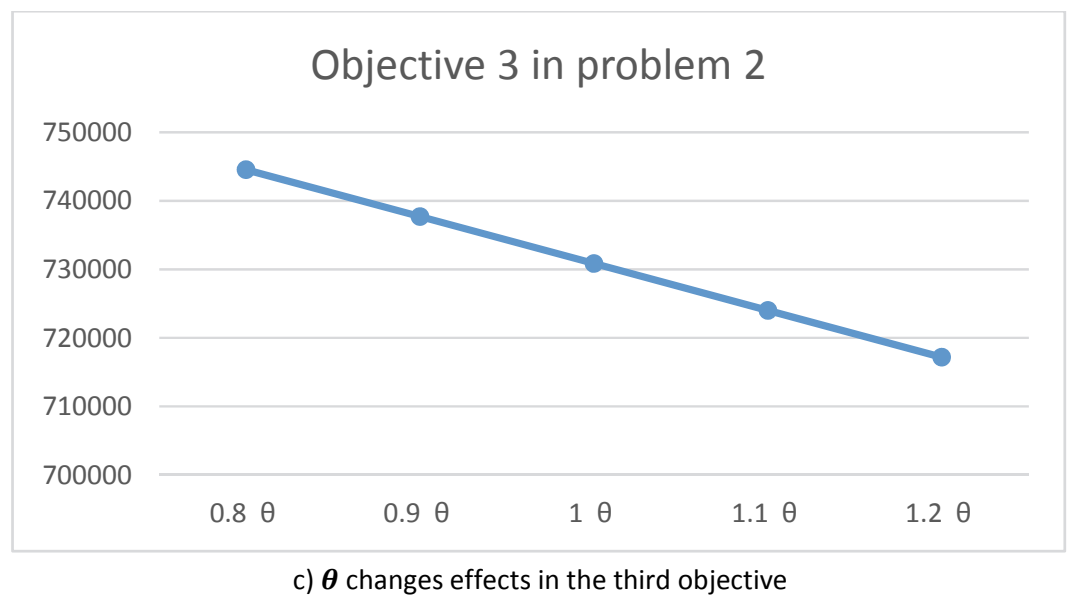

Fig. 10. $\theta$ changes effects on the objectives in problem 2 
As it is indicated from the Fig. 11, objective 1 reduces in problem 1 as $\mathrm{P}^{\mathrm{k}}{ }_{\text {itl }}$ increases. One of its other noteworthy points is that as this parameter increases, the objective 1 changes are gradually reduced. With the increase of fines for satisfying the delayed demands, it is tried to satisfy most of the demands in the first run. Objective 2 increases in problem 1 as $\mathrm{P}^{\mathrm{k}}{ }_{\text {it }}$ increases. One of its other noteworthy points is that as this parameter increases, the objective 2 changes are gradually reduced. With the increase of fines, the chance of satisfying the delayed demands is increased. Objective 3 reduces in problem 1 as $\mathrm{P}^{\mathrm{k}}{ }_{\mathrm{itl}}$ increases. One of its other noteworthy points is that as this parameter increases, the objective 3 changes are gradually reduced. With the increase of this parameter, we are more confident that our available resources can meet the demands.

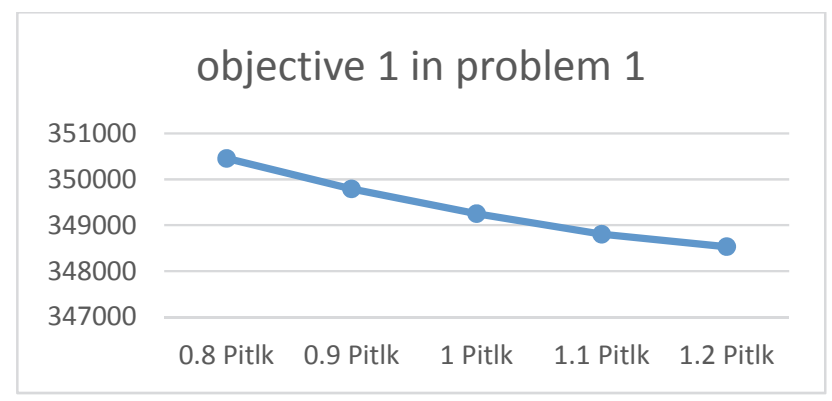

a) $\mathrm{P}^{\mathrm{k}}{ }_{\mathrm{itl}}$ changes effects in the first objective

\section{objective 2 in problem 1}

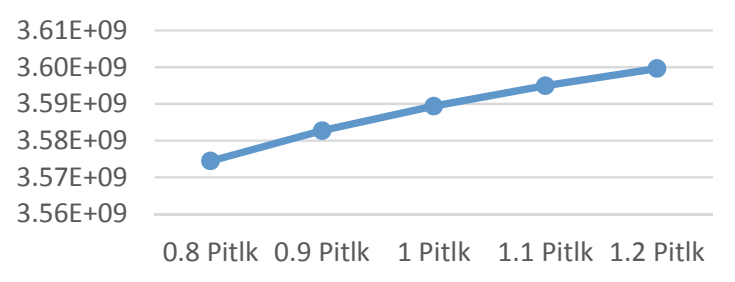

b) $\mathrm{P}_{\text {itl }}$ changes effects in the second objective

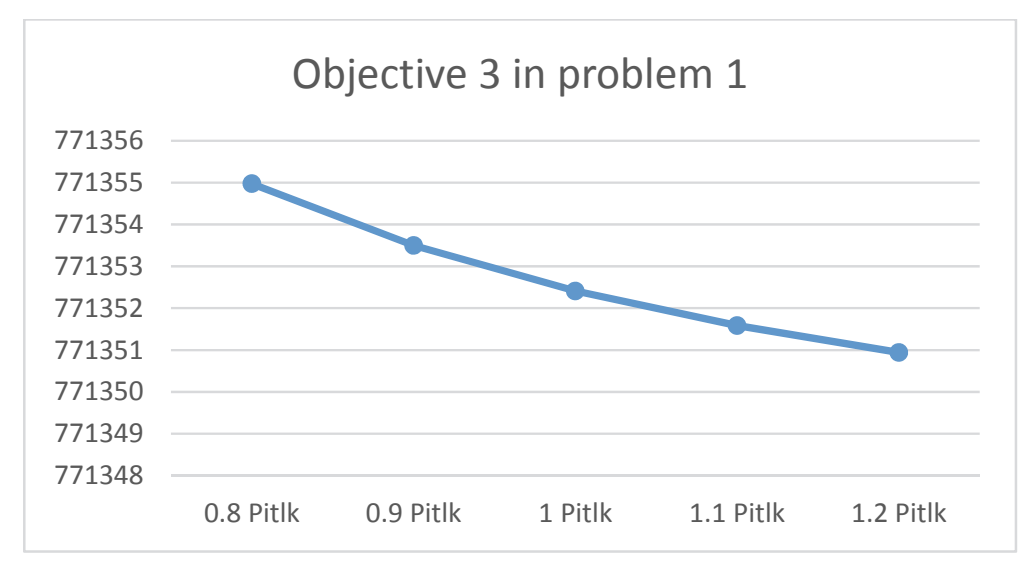

c) $P^{k_{i t l}}$ changes effects in the third objective

Fig. 11. $\mathrm{P}_{\mathrm{itl}}$ changes effects on the objectives in problem 1

As it is seen in the Fig. 12, objective 1 increases in problem 2 as $\mathrm{P}^{\mathrm{k}}{ }_{\text {itl }}$ increases. One of the noteworthy points in this regard is that the changes of objective 1 are gradually reduced as this parameter increases. But after point 1.2 it increases again, in a way that the change of objective function 1 is related to this point. With the increase of fine rate, more costs are generated in the model. Objective 2 increases in problem 2 as $\mathrm{P}^{\mathrm{i}}$ ill increases. One of the noteworthy points in this regard is that the changes of objective 1 are gradually reduced as this parameter increases. With the increase of fine rates, the chance of demand satisfaction with no delay increases. Objective 3 is reduced in problem 2 as $\mathrm{P}^{\mathrm{k}}{ }_{\text {itl }}$ increases. This reduction is with a relatively constant slope. With the increase of fines, the amount of the available resources to meet the demands and the objective function reduces. 
objective 1 in problem 2

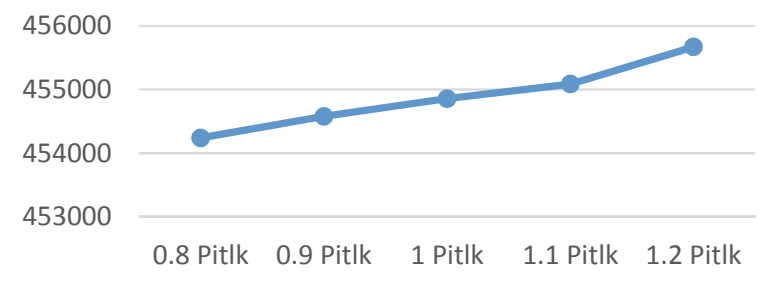

a) $P^{k}{ }_{i t l}$ changes effects in the first objective objective 2 in problem 2

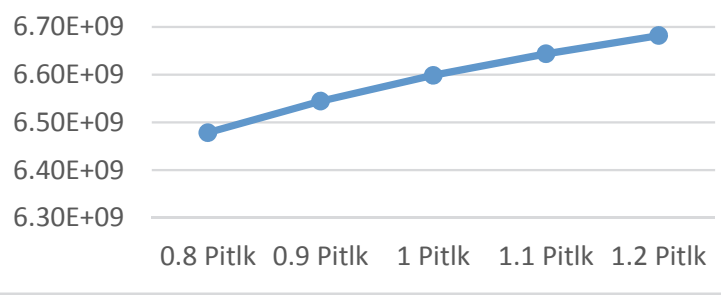

b) $\mathrm{P}_{\text {itl }}$ changes effects in the second objective

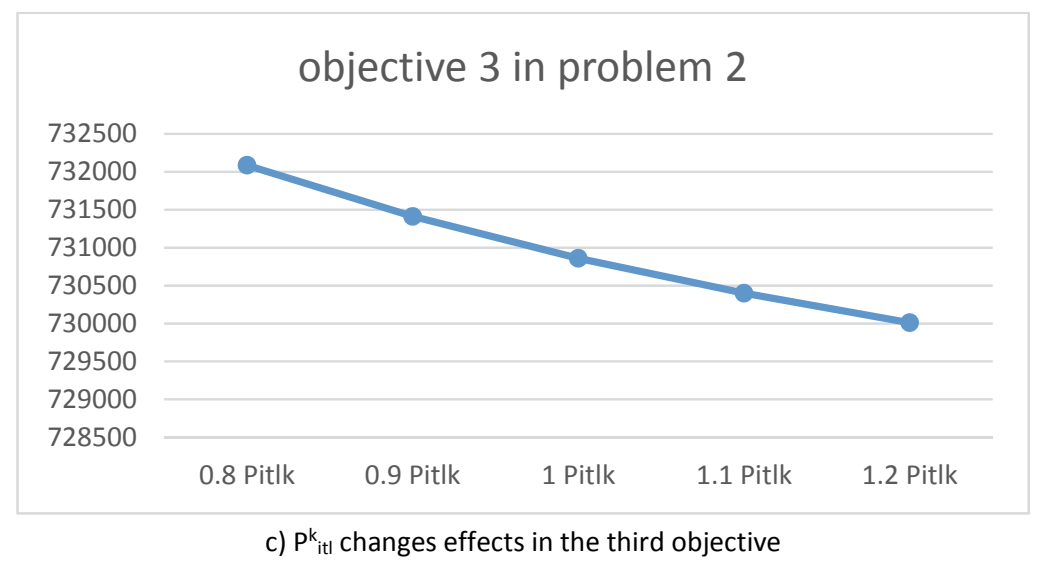

Fig. 12. $\mathrm{P}^{\mathrm{k}}{ }_{\mathrm{itl}}$ changes effects on the objectives in problem 2

As it is shown in the Fig. 13 (a), objective 1 in problem one frequently changes as $\mu$ changes. In a way that for a 10 percent increase of the parameter. Objective 1 doesn't change. Then for another 10 percent increase, it has the maximum increase. For a ten percent reduction, the objective increases and then, for another 10 percent reduction, again the objective reduces so that it reaches its initial amount. With the increase of the capacity, more distribution centers should be established. But, on the other hand, the amount of discounts for the products reduces the cost, but the considerable increase of capacity would lead to more establishment cost in the model, therefore, again, the costs are elevated. As it is shown from the Fig. 13 (b), objective 1 in problem 2 does not change as $\mu$ changes. Objective 1 in this problem only increases for a 20 percent increase of the parameter. With the increase of the feasibility space, no cost is generated until it doesn't lead to establishment of a location for distribution. Although, with the establishment of a distribution location, more cost is generated in the model.

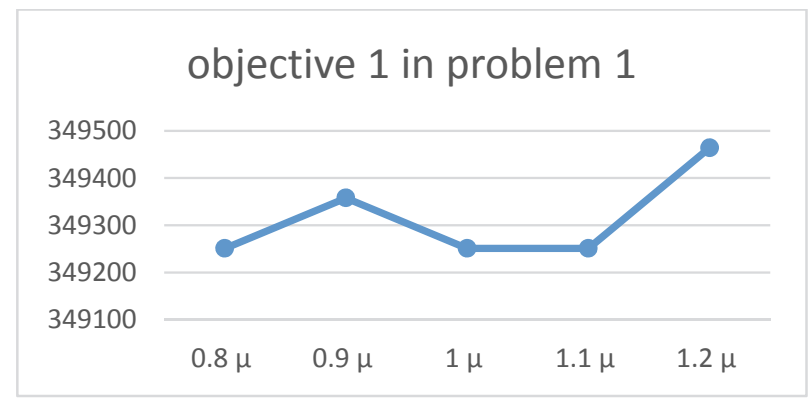

a) $\boldsymbol{\mu}$ changes effects in the first objective in problem 1

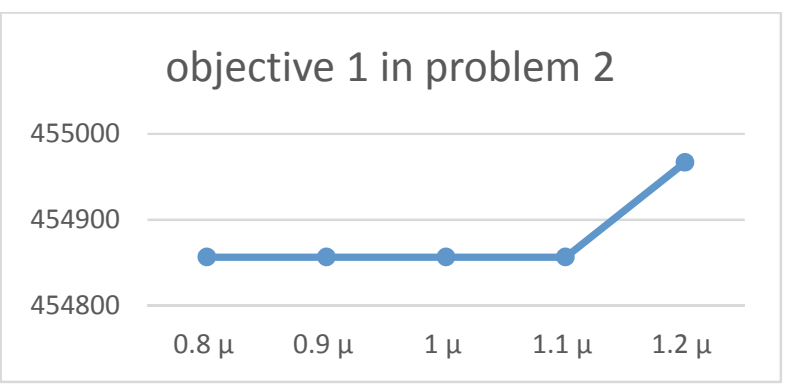

b) $\boldsymbol{\mu}$ changes effects in the first objective in problem 2

Fig. 13. $\mu$ changes effects 
As it is shown in the Fig. 14 (a), objective 1 in problem 1 reduces as $\gamma$ increases. This reduction of objective one is always with a relatively constant slope, except for one point. Compared to other points, the reduction slope of objective 1 is higher in the 20 percent increase range. Through controlling the scenarios and considering their effect upon each other, costs are reduced, because the distributive amounts are determined in a way that can provide the maximum favorability in all scenarios.

As it is shown in the Fig. 14 (b), objective 1 in problem 2 reduces as $\gamma$ increases. This reduction of objective one is always with a relatively constant slope, except for one point. Through controlling the scenarios and considering their effect upon each other, costs are reduced, because the distributive amounts are determined in a way that can provide the maximum favorability in all scenarios.

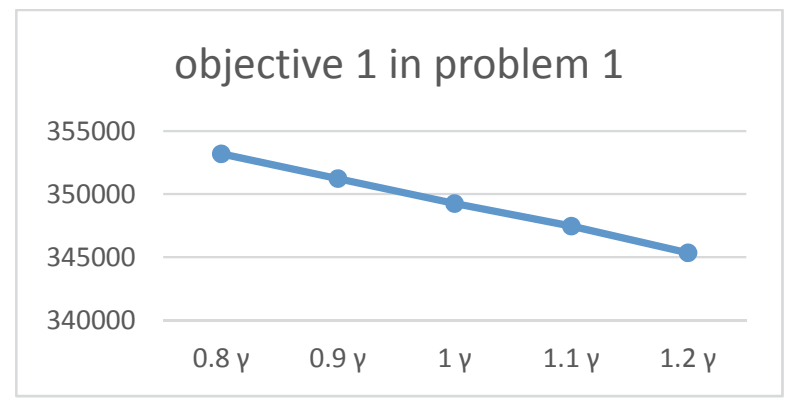

a) $\gamma$ changes effects in the first objective in problem 1

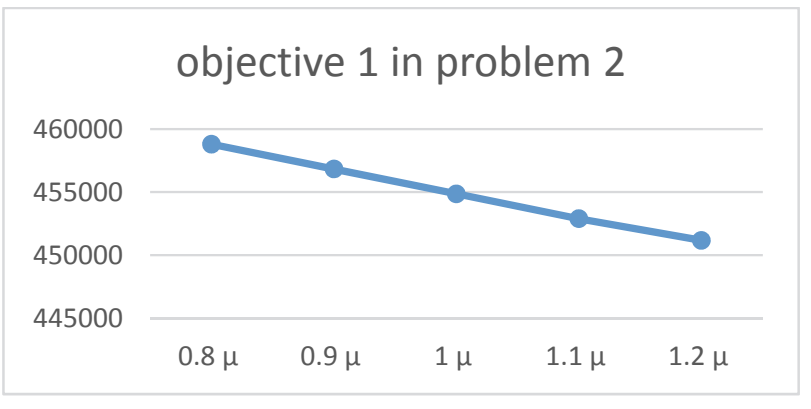

b) $\gamma$ changes effects in the first objective in problem 2

Fig. 14. $\gamma$ changes effects

Considering the presented model, 2 problems were studied. In the first problem, the probability of relief resources accessibility, and in the second problem, demand were studied in a fuzzy form. Regarding the conducted analyses, higher amount of demand were considered for the second problem, which have led to the cost elevation of this problem. On the other hand, the chance of demand satisfaction without delayed orders is higher in the second problem. Moreover, demand satisfaction is also higher in the second problem. Therefore, these problems should be utilized suitable with the problem space.

\section{Conclusion}

Relief at the time of incidents occurrence is of a particular significance for human because of the lethal dangers of incidents. In this article, a multi-objective mathematical model were presented in the uncertainty space for temporary positioning of distribution facilities, so that these facilities could distribute relief commodities at the time of crisis. In the presented model, the concepts of costs, chance of demand satisfaction, elevation of system responding capability, discount levels for relief commodities, satisfaction of demand in a delayed order form, hub for returned and delayed orders compilation and special rout for time importance in distribution of relief commodities. Finally, through using the robust planning, the model were strengthened. Considering the presented model, 2 problems were studied. In the first problem the probability of accessibility and in the second problem, demand were studied in a fuzzy form. Regarding the conducted analyses, higher amounts of demand were considered for the second problem led to the cost elevation of this problem. On the other hand, the chance of demand satisfaction without delayed orders is higher in the second problem. Moreover, demand satisfaction is also higher in the second problem. Therefore, these problems should be utilized suitable with the problem space. We used a NSGA-II algorithm and $\varepsilon$-Constraint method to deal with multi-objectiveness of the problem and solved the problem and performed the sensitivity analysis. Our proposed algorithm showed an appropriate performance. For the future studies, we can use another algorithm to solve the problem and evaluate its performance. 


\section{References}

Aly, A. A., \& White, J. A. (1978). Probabilistic formulation of the emergency service location problem. Journal of the Operational Research Society,29(12), 1167-1179.

Ben-Tal, A., Do Chung, B., Mandala, S. R., \& Yao, T. (2011). Robust optimization for emergency logistics planning: Risk mitigation in humanitarian relief supply chains. Transportation research part B: methodological, 45(8), 1177-1189.

Balcik, B., \& Beamon, B. M. (2008). Facility location in humanitarian relief.International Journal of Logistics, 11(2), 101-121.

Berlin, G. N., \& Liebman, J. C. (1974). Mathematical analysis of emergency ambulance location. Socio-Economic Planning Sciences, 8(6), 323-328.

Ball, M. O., \& Lin, F. L. (1993). A reliability model applied to emergency service vehicle location. Operations research, 41(1), 18-36.

Berman, O., Drezner, Z., \& Wesolowsky, G. O. (2007). The transfer point location problem. European journal of operational research, 179(3), 978-989.

Balcik, B., Beamon, B. M., \& Smilowitz, K. (2008). Last mile distribution in humanitarian relief. Journal of Intelligent Transportation Systems, 12(2), 51-63.

Campos, V., Bandeira, R., \& Bandeira, A. (2012). A method for evacuation route planning in disaster situations. Procedia-Social and Behavioral Sciences, 54, 503-512.

Campbell, A. M., Vandenbussche, D., \& Hermann, W. (2008). Routing for relief efforts. Transportation Science, 42(2), 127-145.

Liou, C. D. (2015). Markovian queue optimisation analysis with an unreliable server subject to working breakdowns and impatient customers. International Journal of Systems Science, 46(12), 2165-2182.

Daskin, M. S. (1983). A maximum expected covering location model: formulation, properties and heuristic solution. Transportation Science, 17(1), 48-70.

Davis, L. B., Samanlioglu, F., Qu, X., \& Root, S. (2013). Inventory planning and coordination in disaster relief efforts. International Journal of Production Economics, 141(2), 561-573.

Doerner, K. F., Gutjahr, W. J., \& Nolz, P. C. (2009). Multi-criteria location planning for public facilities in tsunami-prone coastal areas. Or Spectrum,31(3), 651-678.

Drezner, T. (2007). Casualty collection points: number and population covered. In Proceedings of the southwest Decision Sciences Institute 38th annual meeting (pp. 426-433).

Edrissi, A., Poorzahedy, H., Nassiri, H., \& Nourinejad, M. (2013). A multi-agent optimization formulation of earthquake disaster prevention and management. European Journal of Operational Research, 229(1), 261-275.

Erkut, E., Ingolfsson, A., \& Budge, S. (2007). Maximum availability models for selecting ambulance station and vehicle locations. Technical report.

Erkut, E., Ingolfsson, A., Sim, T., \& Erdoğan, G. (2009). Computational comparison of five maximal covering models for locating ambulances.Geographical Analysis, 41(1), 43-65.

Fiacco, A. V., \& McCormick, G. P. (1990). Nonlinear programming: sequential unconstrained minimization techniques (Vol. 4). Siam.

Guha-Sapir, D., Vos, F., Below, R., \& Penserre, S. (2012). Annual disaster statistical review 2011: the numbers and trends (No. CRED/IRSS). UCL.

Hogan, K., \& ReVelle, C. (1986). Concepts and applications of backup coverage. Management Science, 32(11), 1434-1444.

Hashzemi, S., Shokri, A., Amin Naseri, M. R., \& Akbaripour, H. (2014). Designing an expert system for management of crowding and overcrowding in emergency departments. Journal of Industrial Engineering. 48(2) 281-292.

Hale, T., \& Moberg, C. R. (2005). Improving supply chain disaster preparedness: A decision process for secure site location. International Journal of Physical Distribution \& Logistics Management, 35(3), 195-207.

Jotshi, A., Gong, Q., \& Batta, R. (2009). Dispatching and routing of emergency vehicles in disaster mitigation using data fusion. Socio-Economic Planning Sciences, 43(1), 1-24. 
Karasakal, O., \& Karasakal, E. K. (2004). A maximal covering location model in the presence of partial coverage. Computers \& Operations Research, 31(9), 1515-1526.

Liberatore, F., Ortuño, M. T., Tirado, G., Vitoriano, B., \& Scaparra, M. P. (2014). A hierarchical compromise model for the joint optimization of recovery operations and distribution of emergency goods in Humanitarian Logistics. Computers \& Operations Research, 42, 3-13.

Lin, Y. H., Batta, R., Rogerson, P. A., Blatt, A., \& Flanigan, M. (2009). A logistics model for delivery of critical items in a disaster relief operation: heuristic approaches. Recuperado em, 14 .

Matsutomi, T., \& Ishii, H. (1992, March). An emergency service facility location problem with fuzzy objective and constraint. In Fuzzy Systems, 1992., IEEE International Conference on (pp. 315-322). IEEE.

Mete, H. O., \& Zabinsky, Z. B. (2007). Preparing for disasters: medical supply location and distribution. In Proceedings of the INFORMS conference, Seattle, WA.

Ke, H., \& Liu, B. (2007). Project scheduling problem with mixed uncertainty of randomness and fuzziness. European Journal of Operational Research,183(1), 135-147.

Moeini, M., Jemai, Z., \& Sahin, E. (2015). Location and relocation problems in the context of the emergency medical service systems: a case study.Central European Journal of Operations Research, 23(3), 641-658.

Mulvey, J. M., Vanderbei, R. J., \& Zenios, S. A. (1995). Robust optimization of large-scale systems. Operations research, 43(2), 264-281.

Overstreet, R. E., Hall, D., Hanna, J. B., \& Kelly Rainer Jr, R. (2011). Research in humanitarian logistics. Journal of Humanitarian Logistics and Supply Chain Management, 1(2), 114-131.

Özdamar, L., Ekinci, E., \& Küçükyazici, B. (2004). Emergency logistics planning in natural disasters. Annals of operations research, 129(1-4), 217-245.

Pirkul, H., \& Schilling, D. A. (1988). The siting of emergency service facilities with workload capacities and backup service. Management Science, 34(7), 896-908.

Paul, J. A., \& Batta, R. (2008). Models for hospital location and capacity allocation for an area prone to natural disasters. International Journal of Operational Research, 3(5), 473-496.

ReVelle, C. (1989). Review, extension and prediction in emergency service siting models. European Journal of Operational Research, 40(1), 58-69.

Ratick, S., Meacham, B., \& Aoyama, Y. (2008). Locating backup facilities to enhance supply chain disaster resilience. Growth and Change, 39(4), 642-666.

Rawls, C. G., \& Turnquist, M. A. (2010). Pre-positioning of emergency supplies for disaster response. Transportation research part B: Methodological, 44(4), 521-534.

Rajagopalan, H. K., Vergara, F. E., Saydam, C., \& Xiao, J. (2007). Developing effective metaheuristics for a probabilistic location model via experimental design. European Journal of Operational Research, 177(1), 83-101.

Rahmaniani, R., \& Shafia, M. A. (2013). A study on maximum covering transportation network design with facility location under uncertainty. Journal of Industrial and Production Engineering, 30(2), 78-93.

Swiss, R. (2015). Natural catastrophes and man-made disasters in 2014: convective and winter storms generate most losses. Sigma, (2).

Ukkusuri, S., \& Yushimito, W. (2008). Location routing approach for the humanitarian prepositioning problem. Transportation Research Record: Journal of the Transportation Research Board, (2089), $18-25$.

Schilling, D., Elzinga, D. J., Cohon, J., Church, R., \& ReVelle, C. (1979). The TEAM/FLEET models for simultaneous facility and equipment siting.Transportation Science, 13(2), 163-175.

Sheu, J. B. (2007). An emergency logistics distribution approach for quick response to urgent relief demand in disasters. Transportation Research Part E: Logistics and Transportation Review, 43(6), 687-709.

Swoveland, C., Uyeno, D., Vertinsky, I., \& Vickson, R. (1973). Ambulance location: a probabilistic enumeration approach. Management Science, 20(4-part-ii), 686-698. 
Serra, D., \& Marianov, V. (1996). The location of emergency services in changing network: the case of Barcelona. In Seventh International Symposium on Locational Decisions, Edmonton, Canada.

Shen, Z. J. M., Pannala, J., Rai, R., \& Tsoi, T. S. (2008). Modeling transportation networks during disruptions and emergency evacuations. University of California Transportation Center.

Vitoriano, B., Ortuño, M. T., Tirado, G., \& Montero, J. (2011). A multi-criteria optimization model for humanitarian aid distribution. Journal of Global Optimization, 51(2), 189-208.

Zitzler, E., Deb, K., \& Thiele, L. (2000). Comparison of multiobjective evolutionary algorithms: Empirical results. Evolutionary computation, 8(2), 173-195.

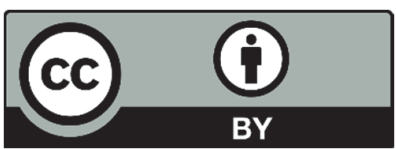

(C) 2016 by the authors; licensee Growing Science, Canada. This is an open access article distributed under the terms and conditions of the Creative Commons Attribution (CC-BY) license (http://creativecommons.org/licenses/by/4.0/). 